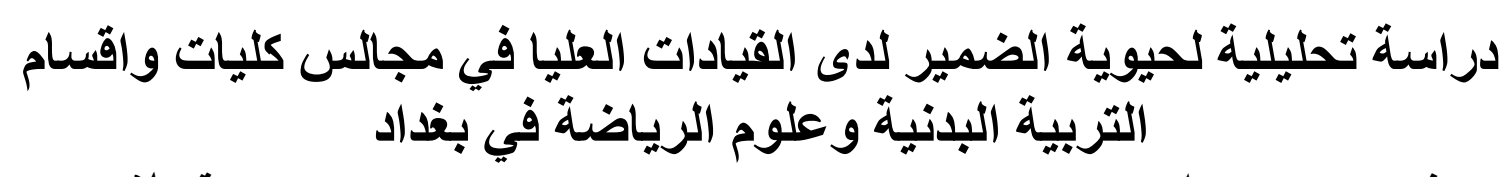

مروة علاء حسين

أ.م.د سندس موسى جواد

aldwltmrwh@gmail.com

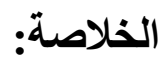

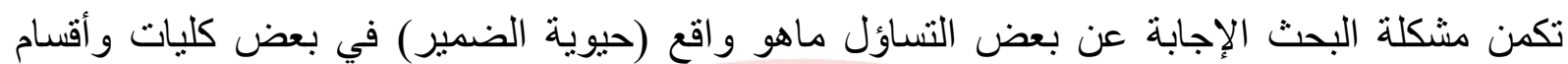

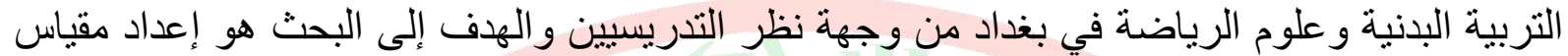

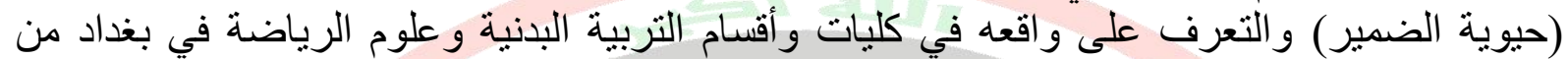

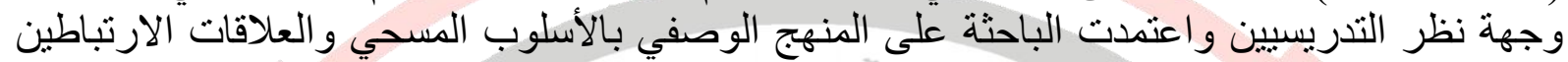

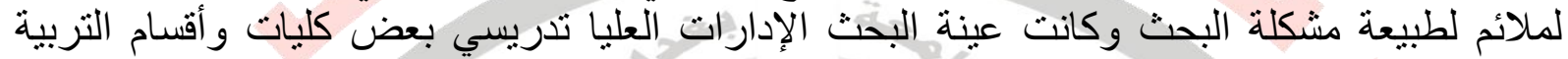

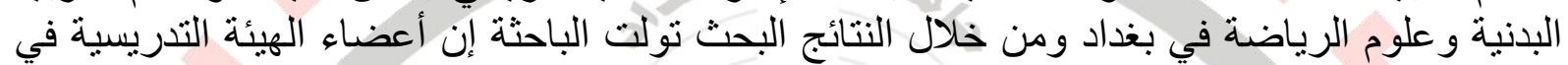

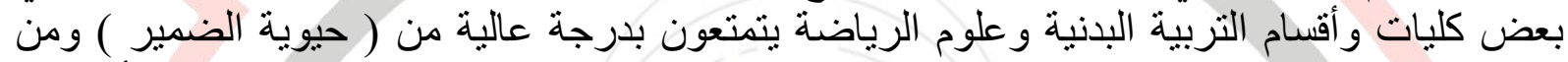

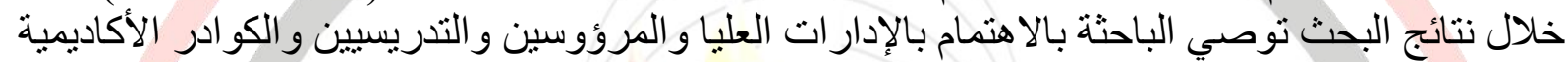

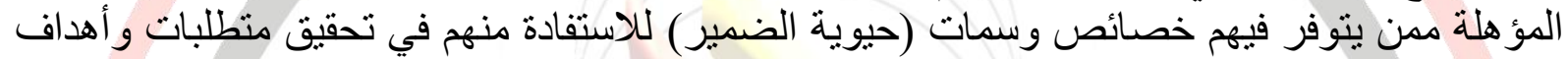

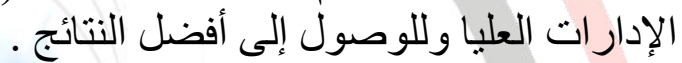
الكلمات المفتاحية (حيوية الضمير , الادارات العليا )

\title{
An analytical study of the vitality of the conscience of the senior leaderships in the boards of colleges and departments of physical education and sports science in Baghdad
}

\section{Extract}

The problem of research lies in answering some of the question: What is the reality of (vital conscience) in some colleges and departments of physical education and sports science in Baghdad from the viewpoint of the teachers? And The aim of the research is to prepare a scale (the vitality of the conscience) and learn about its reality in colleges and departments of physical education and sports science in Baghdad from the viewpoint of teachers and The researcher relied on the descriptive method in the survey method and the relationships related to the nature of the research problem and The sample of the research was senior administrators teaching some colleges and departments of physical education and sports science in Baghdad, Through the results of the research, the researcher assumed that the faculty members in some colleges and departments of physical education and sports science enjoy a high degree of (vital conscience) and Through the results of the research, the researcher recommends paying attention to the higher departments, subordinates, teaching staff and qualified academic cadres who possess the characteristics and characteristics of (vital conscience) to benefit from them in achieving the requirements and goals of the higher departments and to reach the best results.

Keywords (conscience vitality, senior administrations) 


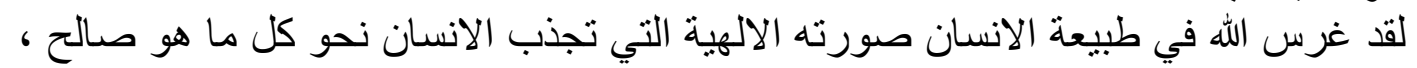

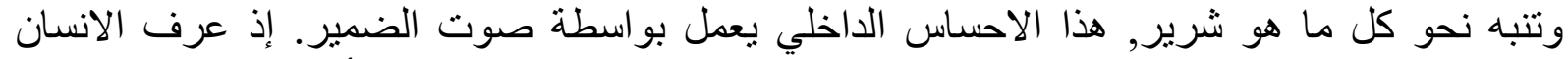

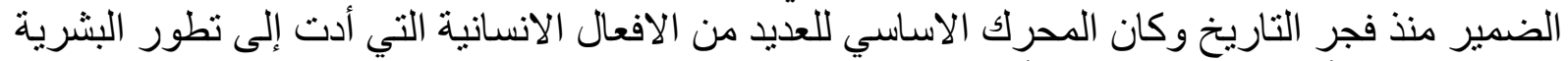

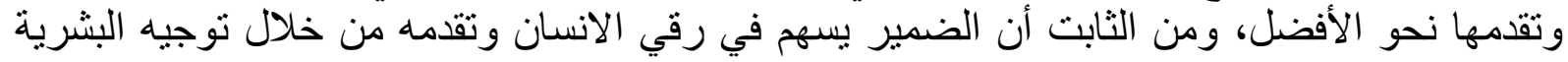

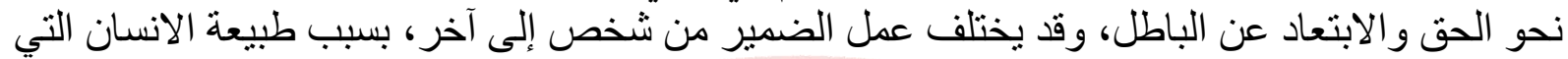

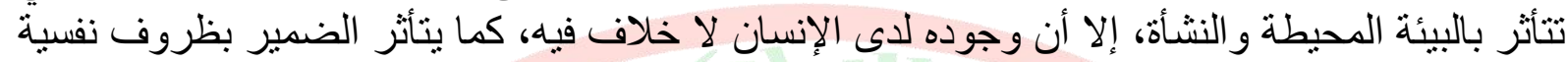

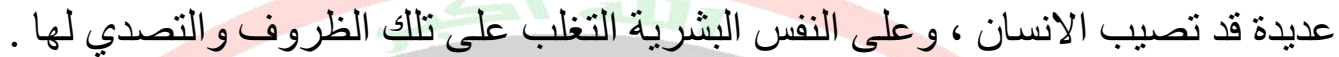

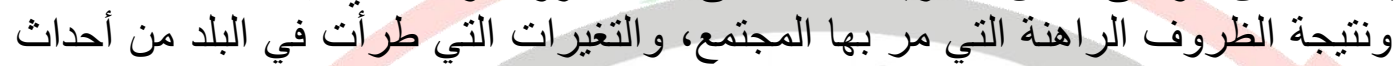

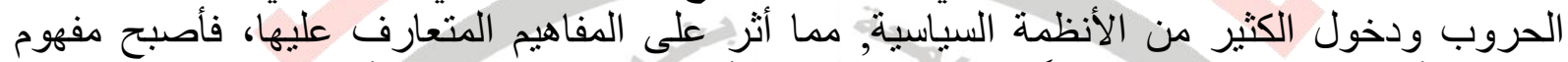

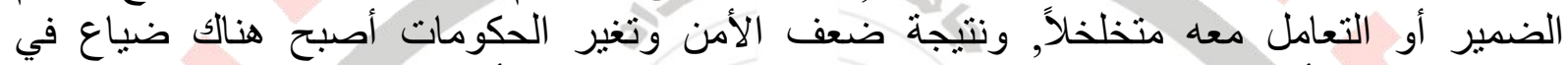

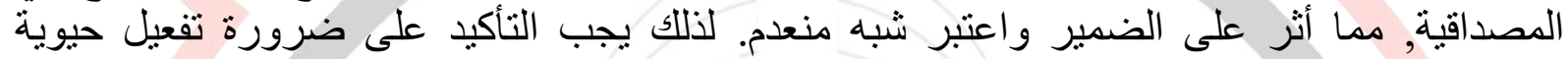

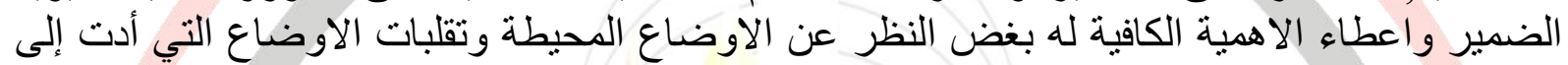

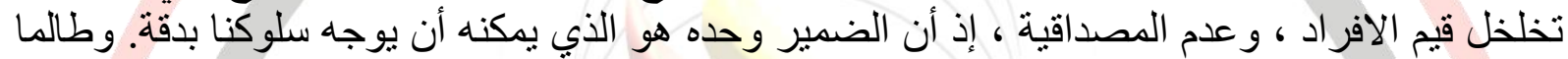

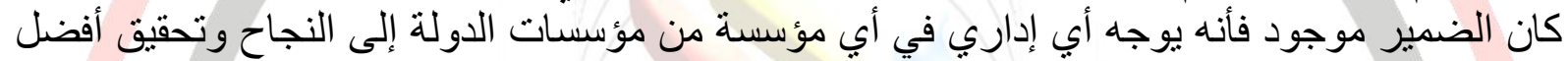

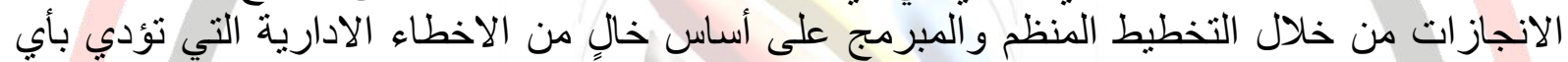

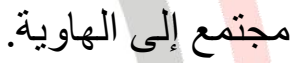

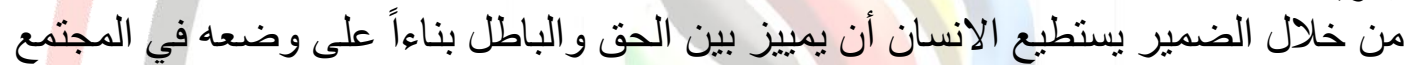

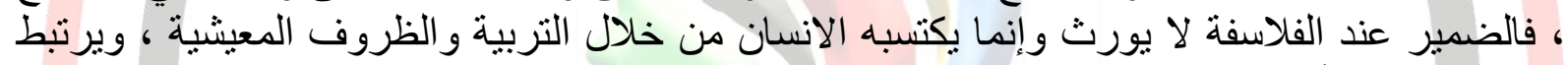

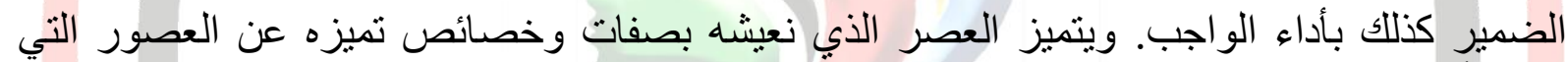

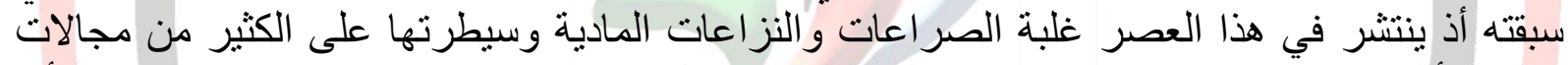

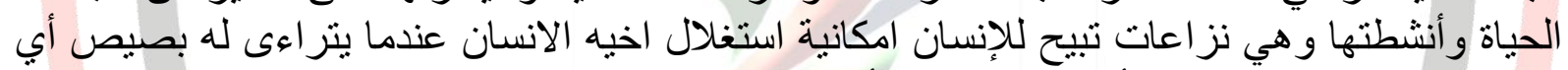

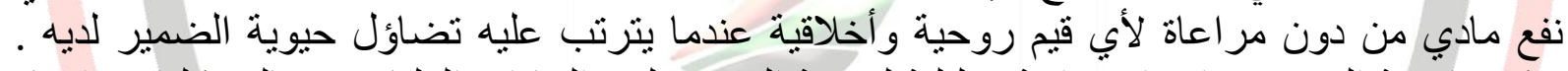

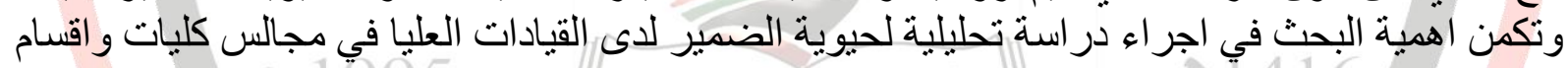

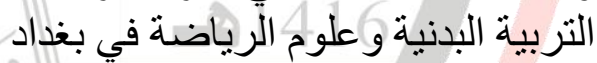

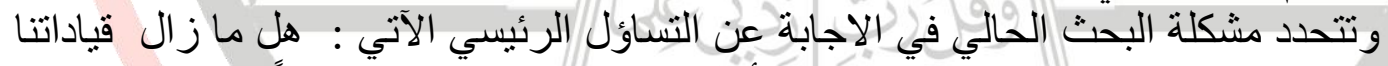

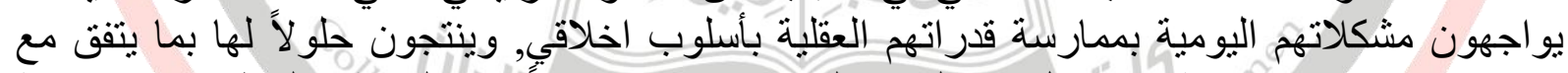

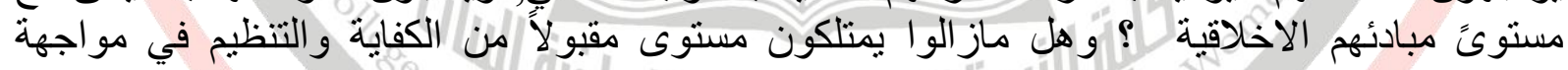

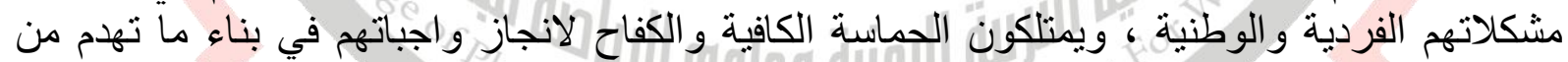

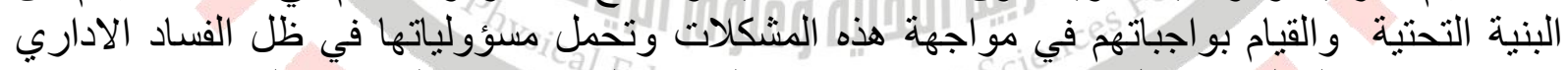

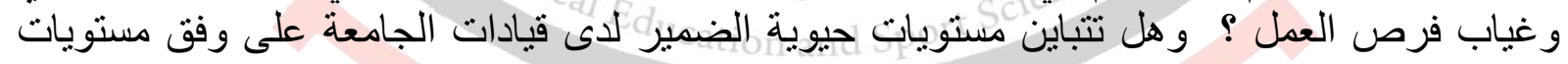
حيوية الضمير لديهرج

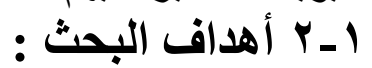
ا ـاعداد مقياس لحيوية الضمير لدى القيادات العاديات العيا من وجهة نظر التدريسين في كليات و اقسام

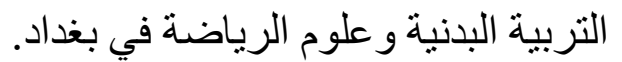

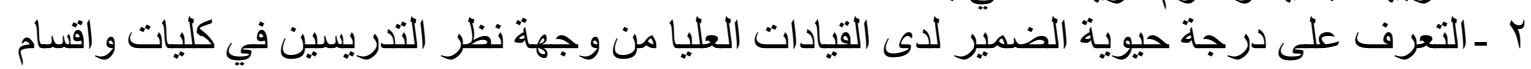
التربية البدنية و علوم الرياضة في بغداد النئ 


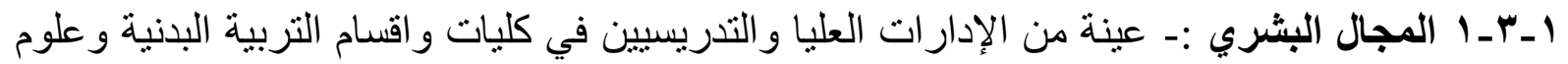

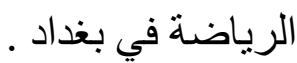

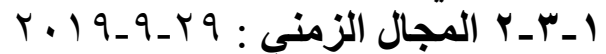

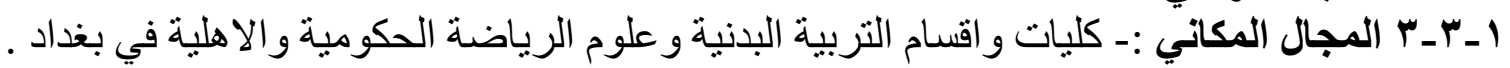
1 ـ ـ تحديد المصطلحات :

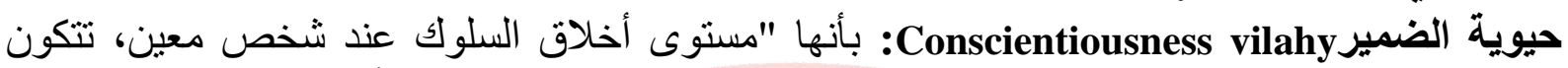

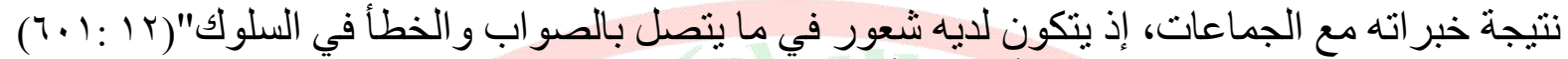

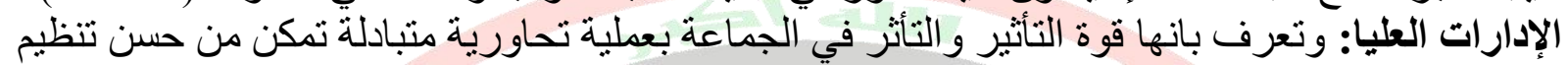

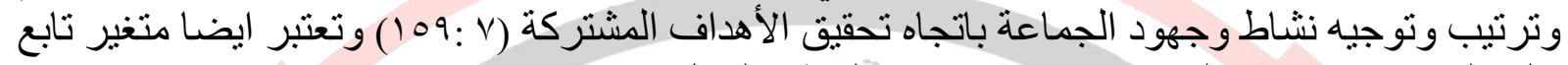

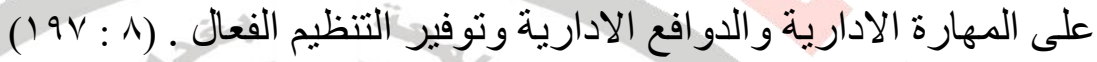

أعتمدت الباحثة على المنهج الوصفي بالاسلوب المسحي والعلاقات الارتباطية لملائمته

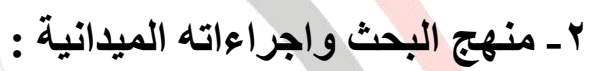
-

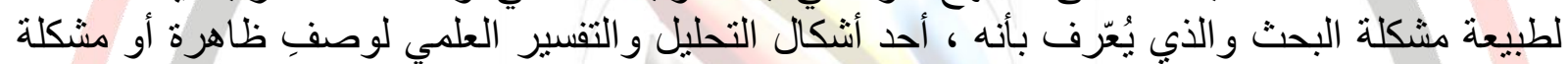
محددة وتصوير ها بالأرقام من خلال جمع البيانات و المعلومات وتحليلها وتفسير ها بطريقة علمية دقيقة.

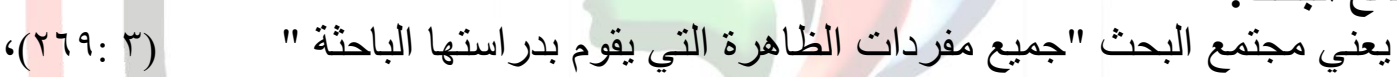

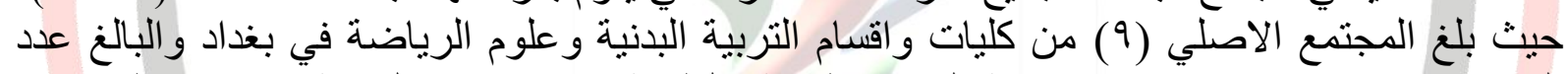

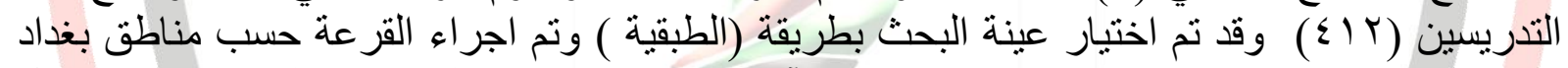

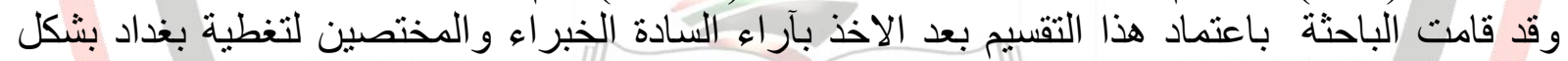

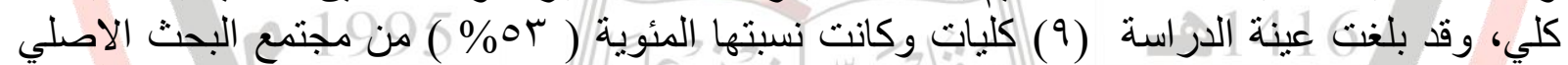

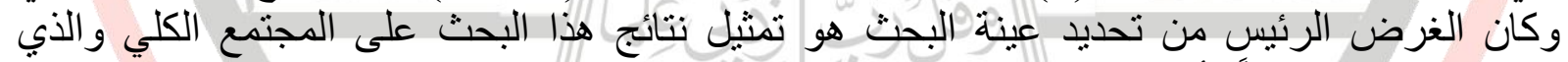

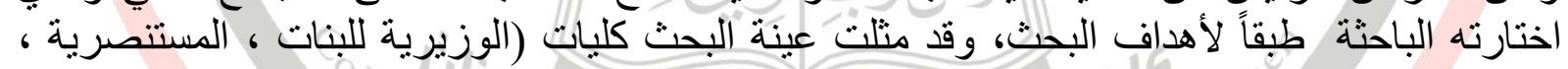

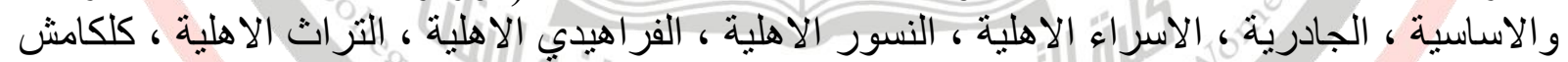

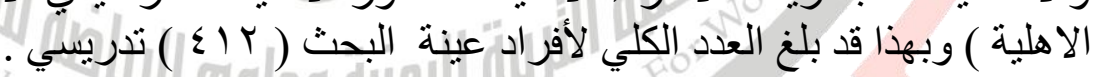

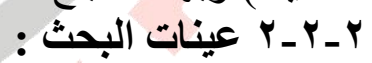
اولا : عينة التجربة الاستطلاعية :

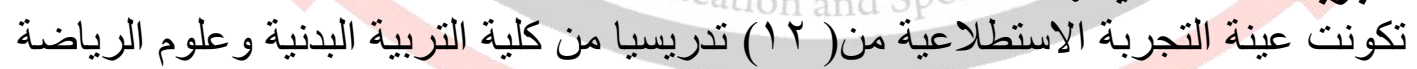

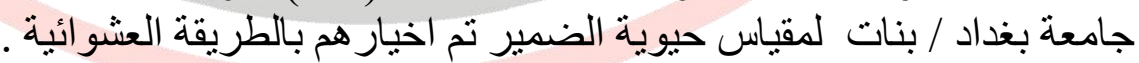

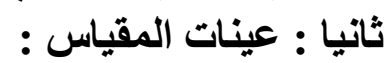

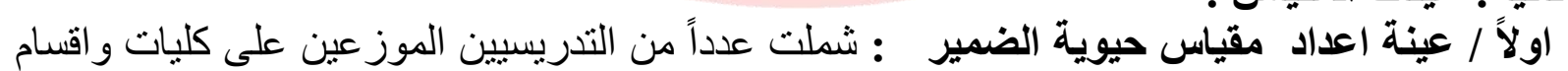

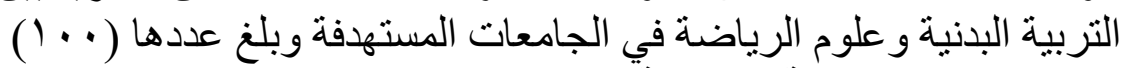

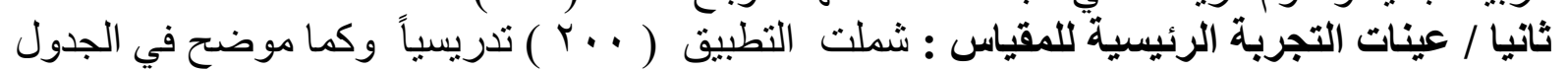




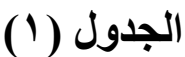

يبين مجتمع البحث وعيناته والنسب المئوية الاعضاء لهيئة التدريسية في كليات واقسام التربية البذنية

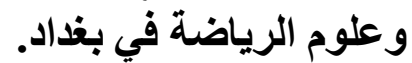

\begin{tabular}{|c|c|c|c|c|c|c|c|c|}
\hline المئوينة & التطبيق & المئوينة & الاعداد & نسبة مئوية & الاستطلاعية & | المجتمع & الجامعة & 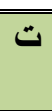 \\
\hline$\% \leqslant r, 1$. & ro & $\%$ \% $r \varepsilon, 1 r$ & $1 \varepsilon$ & $\% \% r \cdot, \curlyvee \wedge$ & Ir & $0 \wedge$ & الوزيرية للبنات & 1 \\
\hline \% \% rr,r. & YI & o\%rr, $\cdot V$ & 10 & - & - & 70 & المستنصرية & r r \\
\hline$\% 01,17$ & Yr & $\%$ r.,rq & 9 & - & 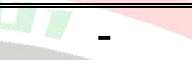 & $\varepsilon r$ & الاسكاسية & $r$ \\
\hline \%\%r,,0Y & $\overline{Y Y}$ & $0 \%$ Y, , O & YY & - & - & $1 \cdot V$ & الجادرية & 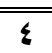 \\
\hline$\%$ & rY & \%६ & 1.3 & - & - & ro & الاسر اء الاهلية & 0 \\
\hline$\%$ \% & YY & \% & $\bar{V}$ & - & - & $r$. & النسور الاهلية & 7 \\
\hline$\% \wedge \wedge, \leqslant \wedge$ & YY & $\% r v, \cdot r$ & 1. & - & - & YV & الفرا هيدي الاهلية & V \\
\hline \% & $F r$ & \% \% rr, rr & V & - & - & $r$. & التراث الاهلية & $\bar{\Lambda} \wedge$ \\
\hline$\% \% \wedge 1,\{\wedge$ & rY & \%\%rY,Yr & 7 & - & - & TV & كلكامش الاهلية & 9 \\
\hline$\% \leqslant \wedge, \leqslant 0$ & r.. & $0 \% r \varepsilon, r v$ & 1. & 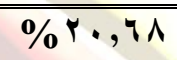 & IT & \&ा & الم & \\
\hline
\end{tabular}

\section{r r r الوسائل والأدوات والأجزةة المستعملة في البحث :}

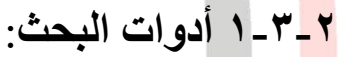

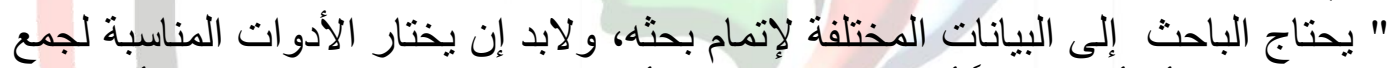

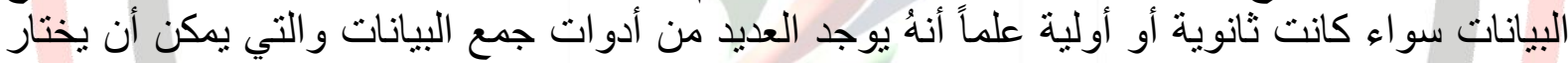

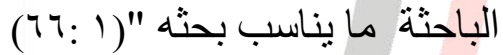

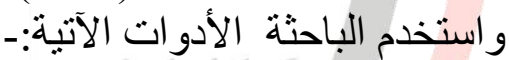

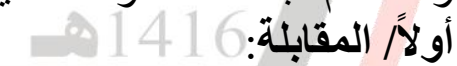
أجرت الباحثة مجمو عة من المقابلات الثخصية مع عدد من الخبراء و المختصين لجمع المعلومات التي

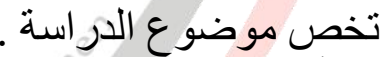
ثانياً : الاستبيان مورع

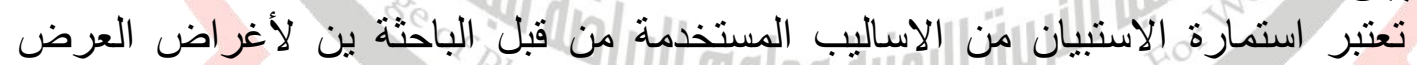

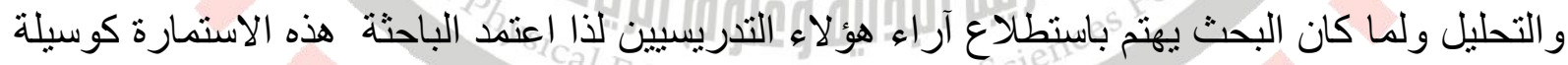
رئيسية لجمع البيانات التي قامت الباحثنة بتصنيمها.

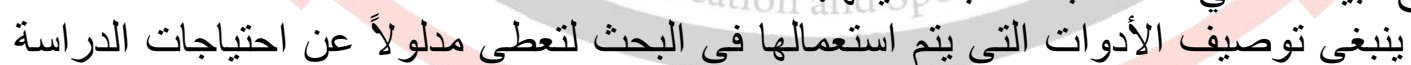

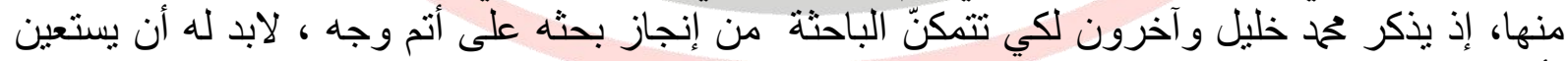

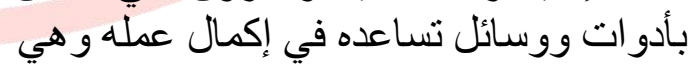

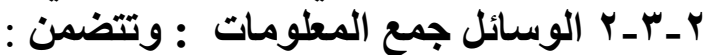

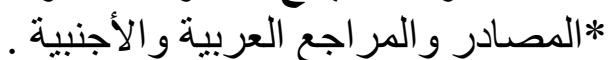

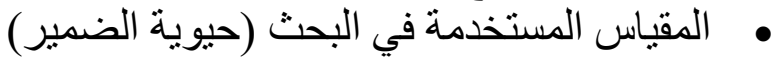

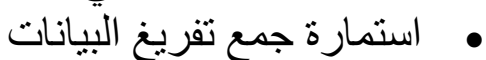

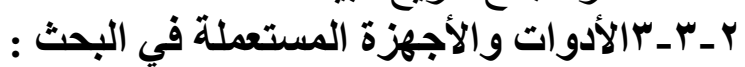




$$
\begin{aligned}
& \text { جهاز حاسوب نوع (hp) عدد (1) ) }
\end{aligned}
$$

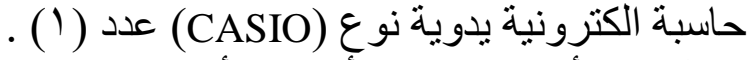

$$
\begin{aligned}
& \text { قرطاسية وأدوات مكتبية (أور اق و أقلام) } \\
& \text { r- بـ إجراءات البحث الميدانية : }
\end{aligned}
$$

لتحقيق أهداف البحث الحالي تطلب, اعدان البحاد مقياس (حيوية الضمير) لذا قامت الباحثة بالإجر اءات الأتية:

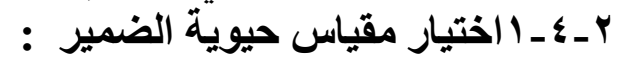

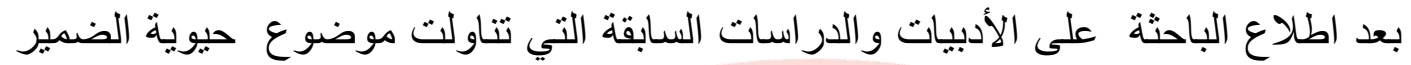

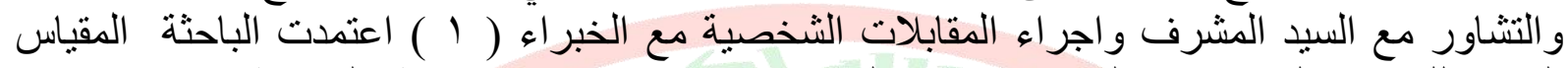

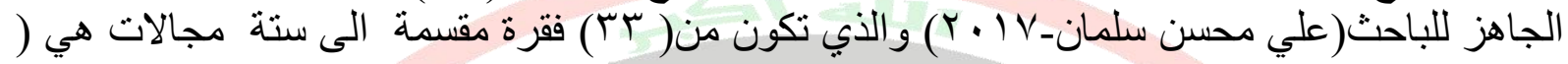

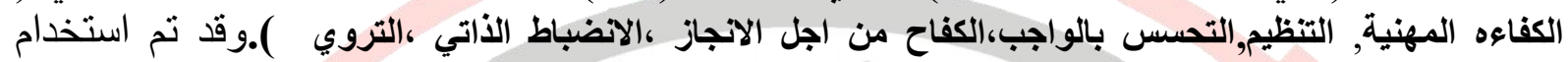

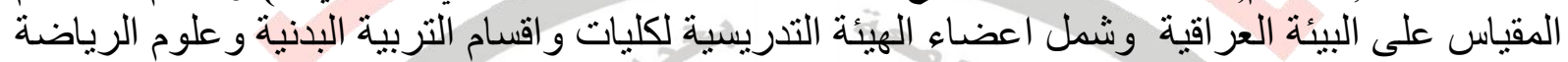

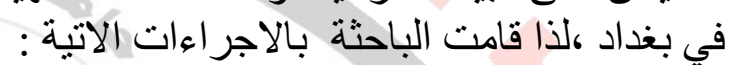

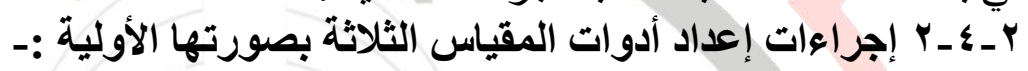

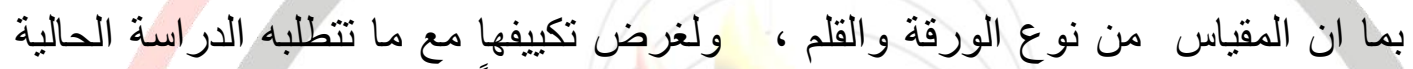

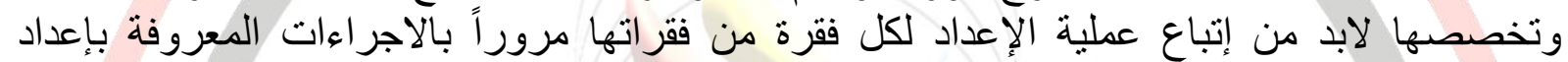

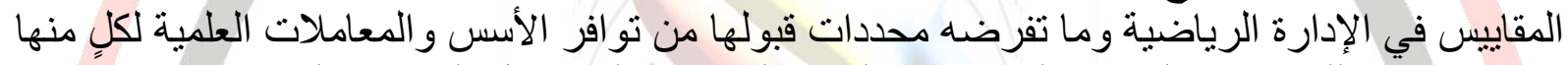

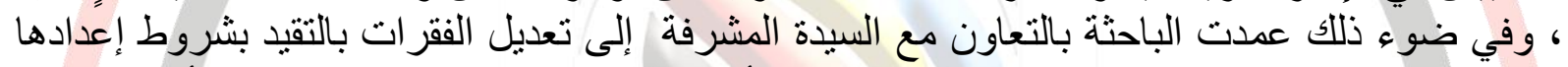

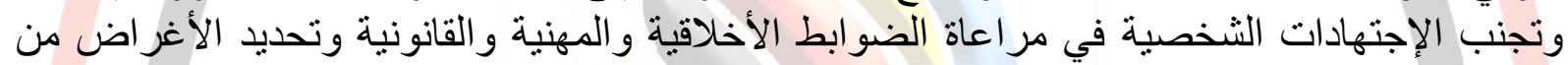

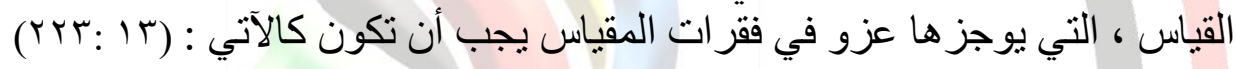
ا ـ قصيرة لاتزيد عن عشرين كلمة .

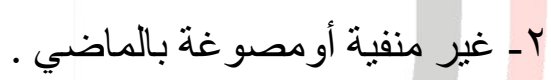

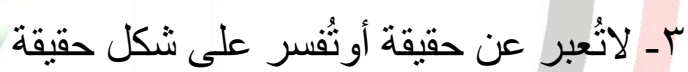
ع - تحوي فكرة واحدة بسيطة غير مركبة.

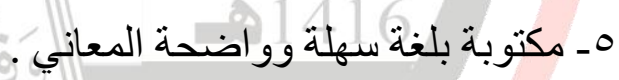

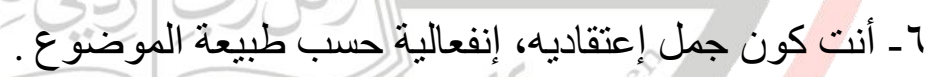

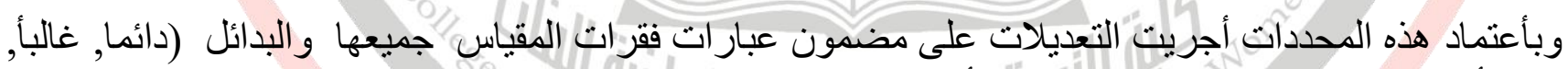

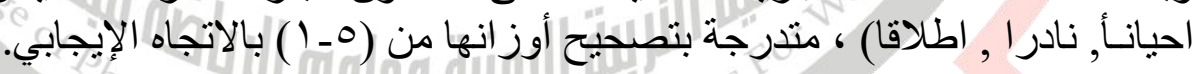

\begin{tabular}{|c|c|c|c|c|c|}
\hline اطلاقا & نادرا & احيانأ & غالباً & دائماً & بائل الاجابة \\
\hline$T$ & $\bar{r}$ & $\bar{r}$ & $\underline{\varepsilon}$ & $\overline{0}$ & الوزن \\
\hline
\end{tabular}

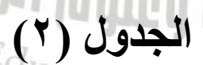

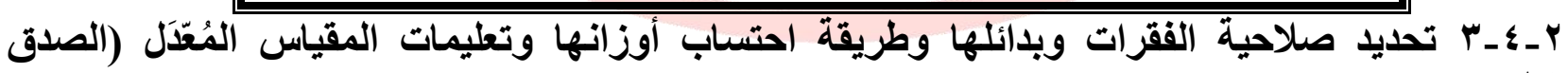

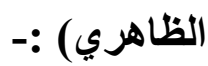

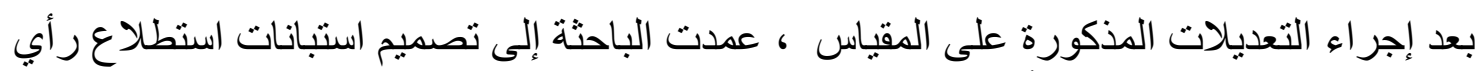

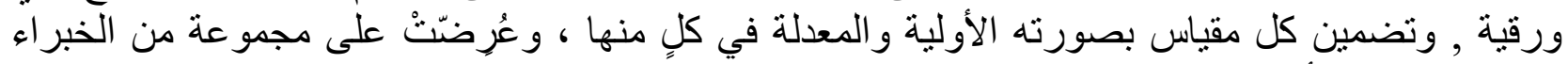
و المتخصصين الأكاديميين البالغ عددهم (10) لاستحصنّال اتفاقهم و المداولة معهم عن التعديلات الخاصة 


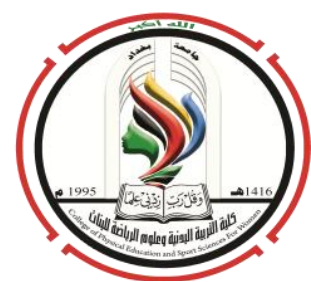

بكل فقرة من فقرات كلٌ من المقاييس الثلاث على حدة ، بعد استخر اج اتفاق آرائهم باستخدام قانون ( كاي

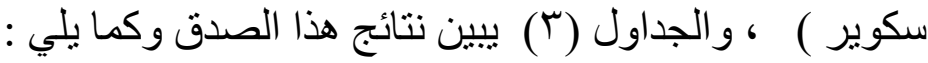

جدول (ب) (ب)

يبين الصدق الظاهري لإعداد فقر ات مقياس حيوية الضمير

\begin{tabular}{|c|c|c|c|c|c|c|}
\hline عدةد & المحذراته & & الفقرات المُعدلة & الفقرات & & \\
\hline الاتفاق & & العدد & تسلسلها & التعديل & & \\
\hline 7 & - & 7 & جميعها & 7 & الكفاءة المهنية & 1 \\
\hline ○ & 1 & ○ & جميعها ج ج) & 7 & التنظيم & $r$ \\
\hline 0 & 1 & 0 & جميعها & 7 & التحسس بالواجب & $r$ \\
\hline o & 1 & $\bullet$ & جميعها & 7 & الكفاح من اجل الانجاز & $\varepsilon$ \\
\hline 7 & - & 7 & جميعها & 7 & الانضباط الذاتي & 0 \\
\hline 7 & - & 7 & جميعها & 7 & التروي & 7 \\
\hline$r r$ & $r$ & & $r \mu$ & $r q$ & & \\
\hline
\end{tabular}

- : _ _ _ التجربة الاستطلاعية

و هي تجربة مصغرة تطبق على عينة صغيرة من نفس مجتمع البحث تجري تحت ظروف

مشابهة لظروف التجربة الرئيسة الهدف منها: التهاء > التعرف على الاخطاء و المعوقات.

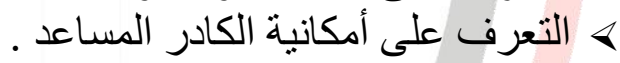

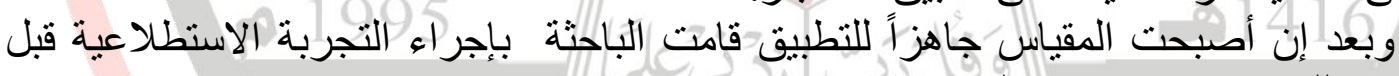

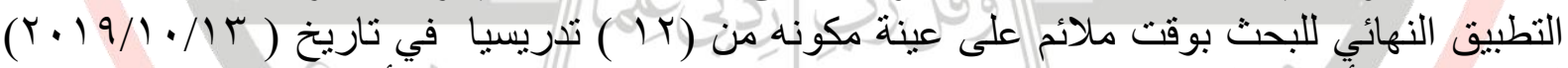

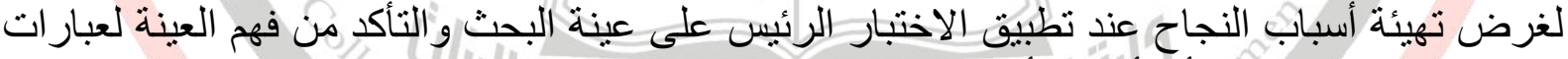
المقياس ومن اجل تلافي أي أخطاء أو صعوبات عند التطبيق خلال الاختبار الرئيس للبحئ.

ץ ـ ـ ـ ـ ا 1 : الصدق التمبيزي تلفي للمقياس:-

أن تعديل محتوى مضدون عبار ات الفقرات وتعديل عدد البدائل للفقرات سيؤثر على القدرة

التمبيزة ، لذلك أوجدت الباحثة القدرة التمييزية لفقرات المقياس المُعدلة بأعتماد طريقة المجمو عتين الطرفيتين

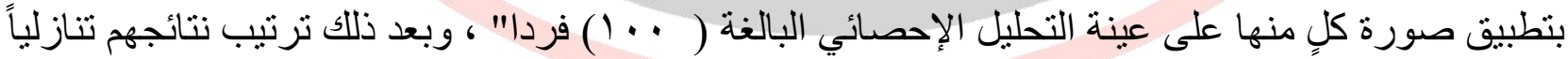

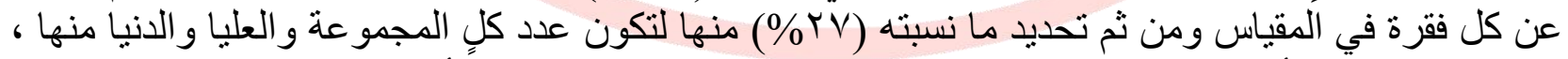

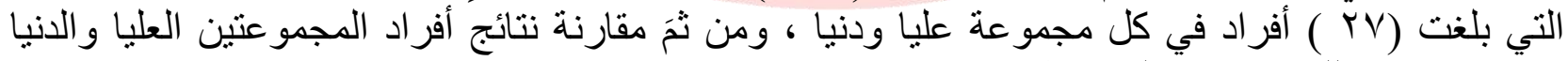
بقانون (t-test) للعينات غير المتر ابطة

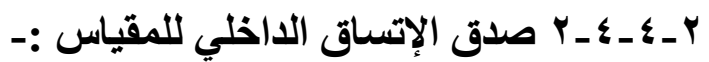

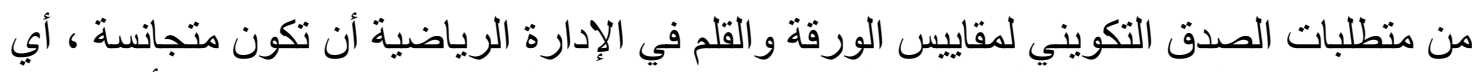
أن تسير أوزان فقر اتها مع الدرجة الكلية للمجال و المقياس المنتمية إليه على نسق والاحد في زيادة أو نقصان 
الدرجة ، وبما أن فقر ات المقياس حققت صدق تمييزي ولم تُحذف أبي منها ، عمدت الباحثة إلى إعتماد درجات تطبيق المقياس على عينة التحليل الإحصائي نفسها .

وإيجاد هذهِ العلاقات الإرتباطية بالمعالجة الإحصائية بمعامل الإرتباط البسيط (person)

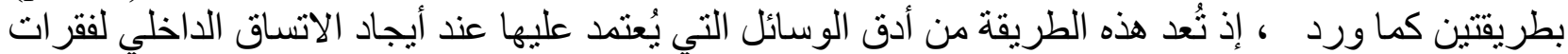
المقاييس.

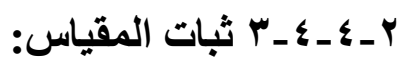
r r - צ-

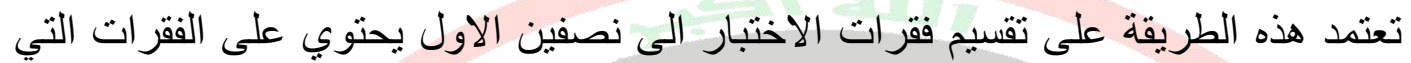

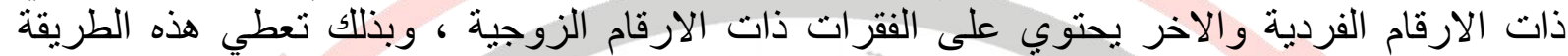

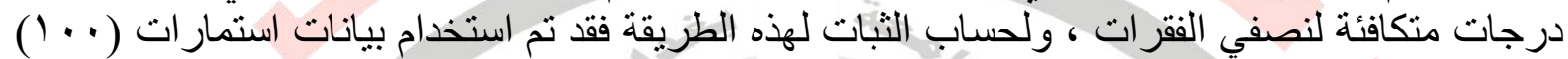

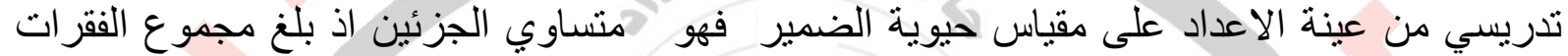

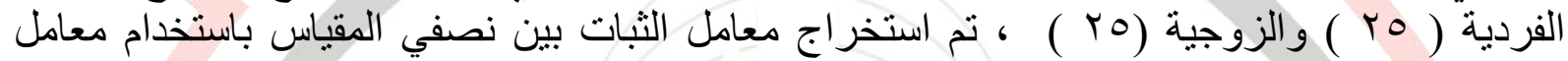
الارتباط (بيرسن البسيط) ونم تعديل قيمت معامل ثبات نصف الاختبار بمعادلة دلالة ثبات (سبيرمان

استعملت الباحثة طريقة الفا كرو نباخ لأنها تستعمل في اي نوع من الناخ الاسئلة الدقالية

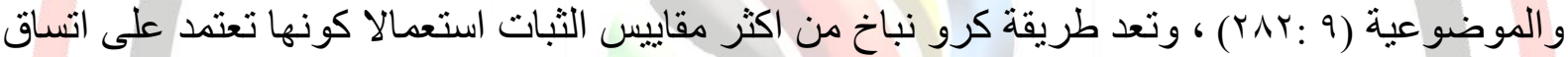

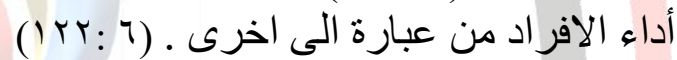
ولحساب الثبات بمعامل الفا كرو نباخ لمقياس حيوية الضمير اعتمدت الباحثة على على عينة

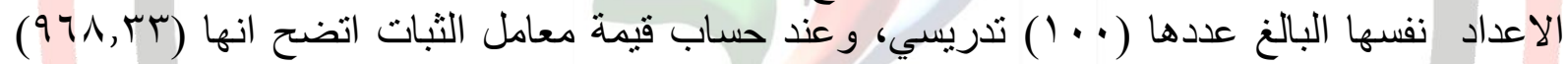

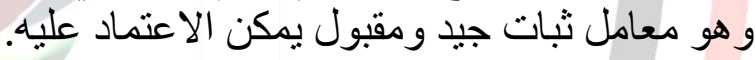
r بـ ــ المقياس بصورته النهائية

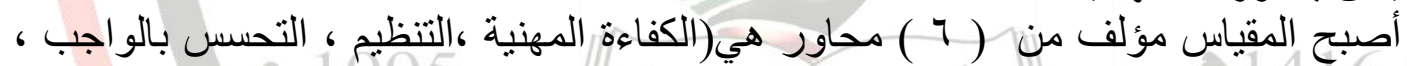

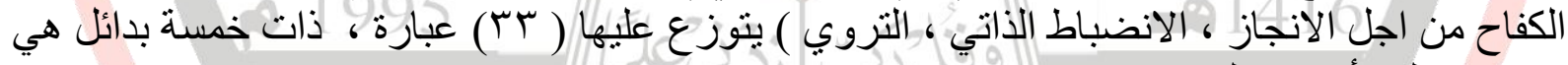

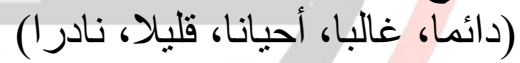

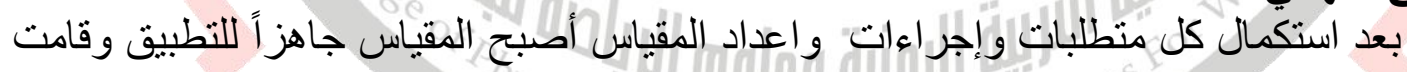
ب- بـ التطبيق النهائي

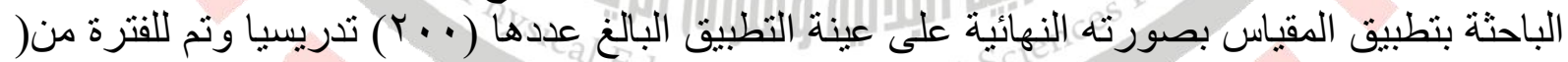

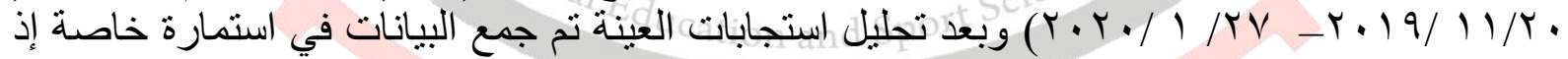
أصبح لكل شخصا درجة خاصة بالها

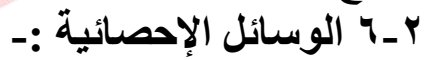

ولجت نتائج الدر اسة آلياً باستعمال برنامج الحقيبة الإحصائية للعلوم الاجتماعية (SPSS) الإصدار (Y0)

r- عرض مقياس حيوية الضمير وتحليلها ومناقشتها بعد اجراء عملية قياس المتغيرات عبر تطبيق المقاييس والحصول الفير على البيانات وتحقيقاً لهدف الدراسة المنضمن (دراسة تحليلية لحيوية الضمير لدى القيادات العليا في مجالس كليات واقسام 


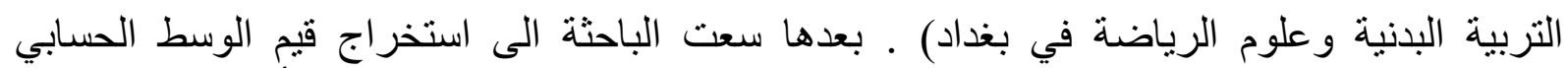

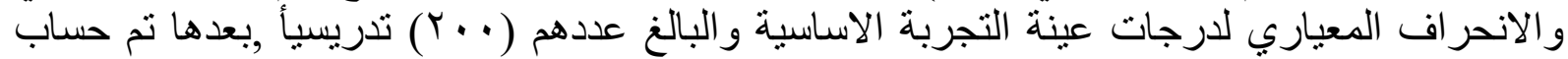
قيمة الوسط الفرضي للمقاييس.وحسب الجدول النيان الناه

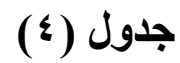

يبين دلالة الفروق بين الوسط الحسابي المتحقق والوسط الحسابي الفرضي للمقياس حيوية الضمير ومجالاته

\begin{tabular}{|c|c|c|c|c|c|c|c|}
\hline \multirow{2}{*}{ الاحصائية } & \multicolumn{2}{|r|}{ قيمة (ت) } & \multirow{2}{*}{ الحرجية } & \multirow{2}{*}{ الفرضي } & \multirow{2}{*}{ الالاتحراف } & \multirow{2}{*}{ الحسابي } & \multirow[t]{2}{*}{ لمتغيرات } \\
\hline & الجدولية & المحسويبة & & & & & \\
\hline مغنوي & $1,7 V$ & $|r, \leqslant|$ & 199 & 99 & $r M, r r$ & $\mid r \cdot, \leqslant 1$ & الكلية \\
\hline & 1.7 & \& \& Wy & 109 & 11 & 7 & & للمفياس \\
\hline مغنوى & 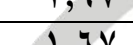 & 19.40 & 199 & $\frac{10}{10}$ & 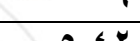 & $\frac{19.98}{19.90}$ & التنظقه المهريج \\
\hline مغنوي & $1,7 \mathrm{~V}$ & $r ., r Y$ & 199 & 10 & $0, .90$ & $r \cdot, r Y$ & التحسن بالو اجب \\
\hline معنوي & $1,7 V$ & $r \cdot, Y \leq$ & 199 & 10 & $\theta, \mu \backslash \wedge$ & $r \cdot, r \leqslant$ & الكفاح من اجل \\
\hline معنوي & $1, T \mathrm{~V}$ & $11, .9$ & 199 & 11 & 7,917 & Yr,\&) & الانضباط الذاتى \\
\hline معنوي & $1,7 \mathrm{~V}$ & $q, v$ & 199 & 11 & $v, r r$ & $r r, \cdot r$ & التروي \\
\hline & & & & & & & \\
\hline & & & & & & & \\
\hline
\end{tabular}

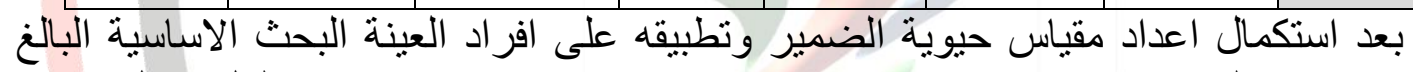

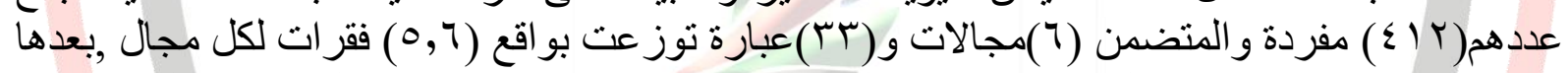

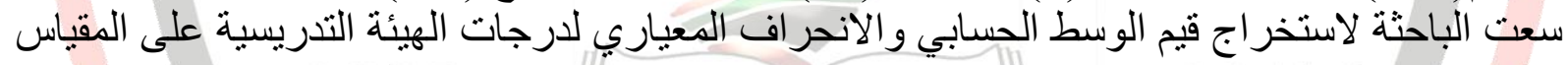

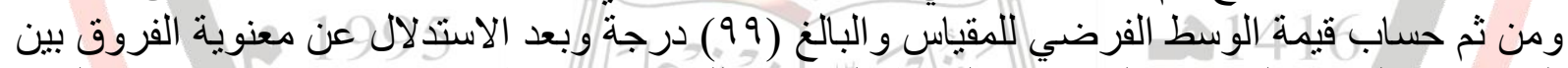

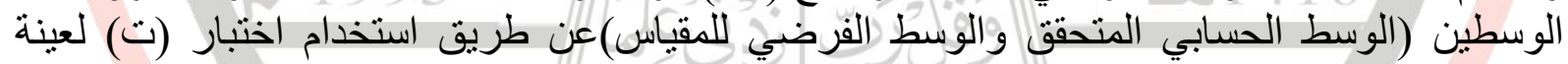

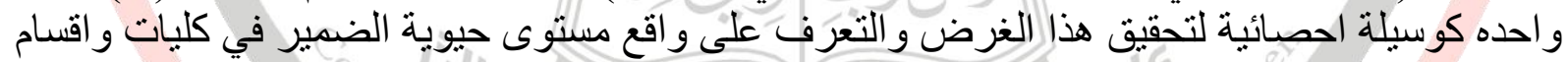

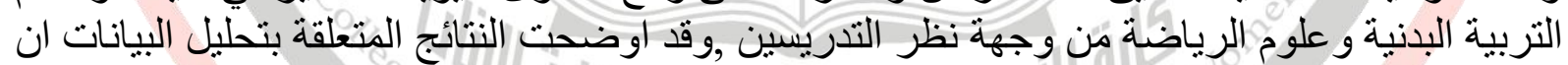

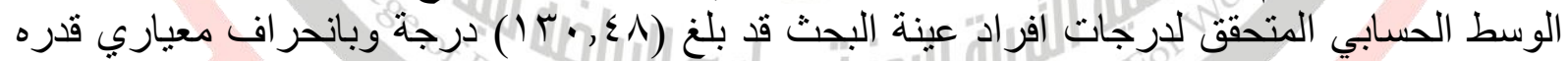

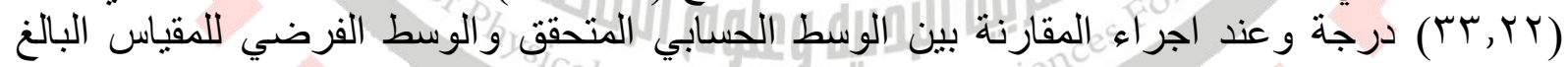

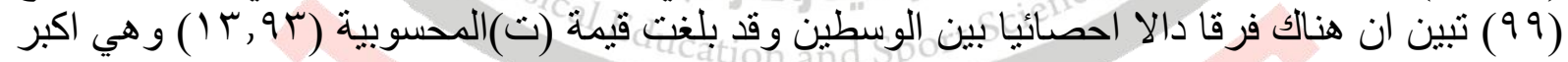

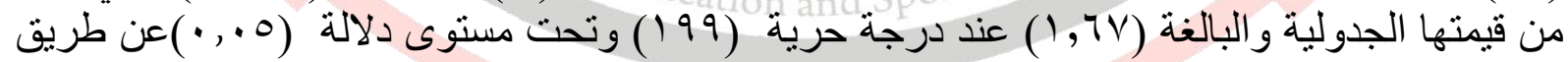

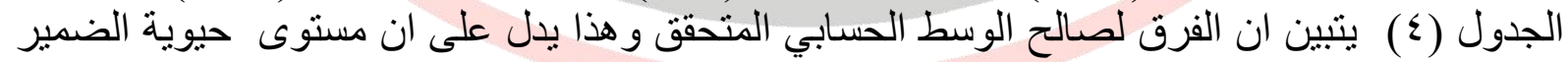

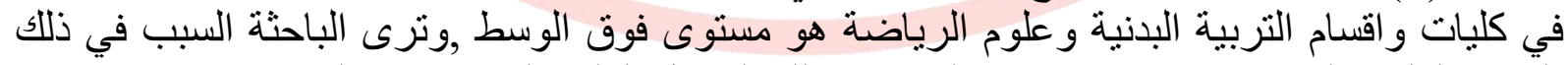

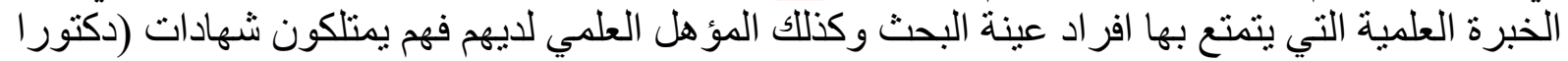

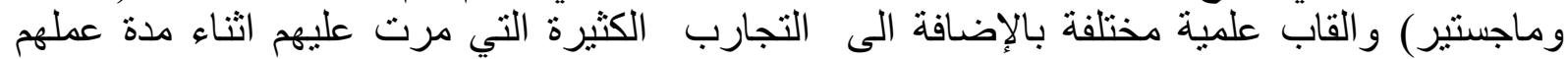

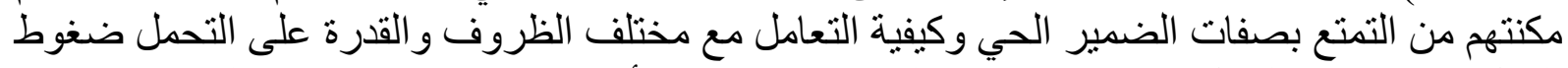

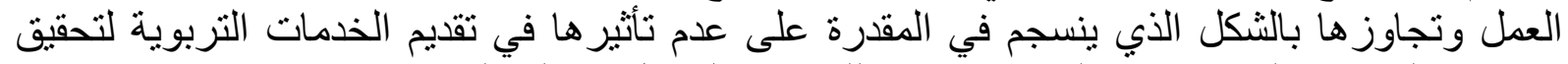

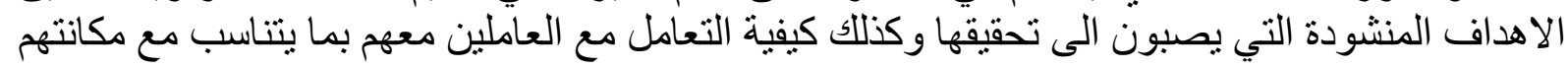
الوظيفية و الجو انب الثخصية و النفسية لهم النيف 


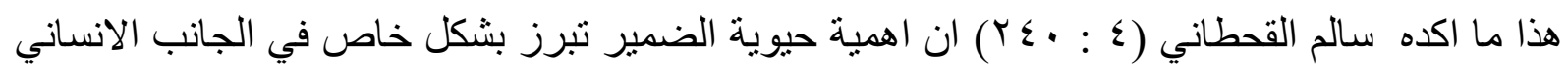

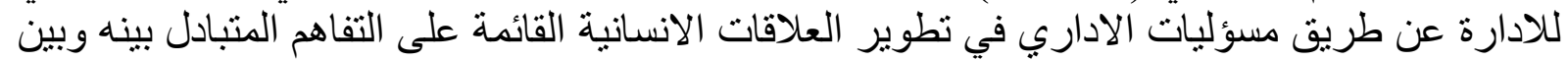

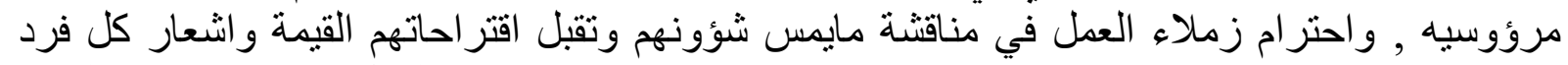

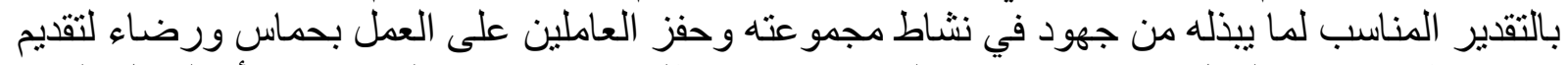

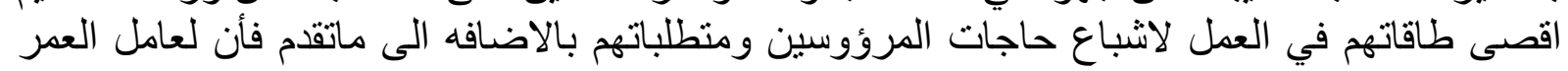

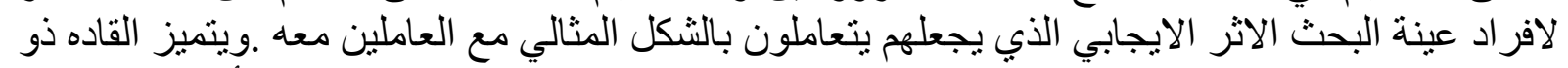

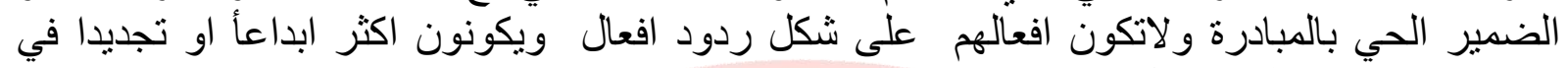

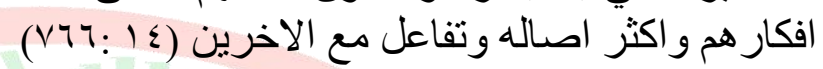

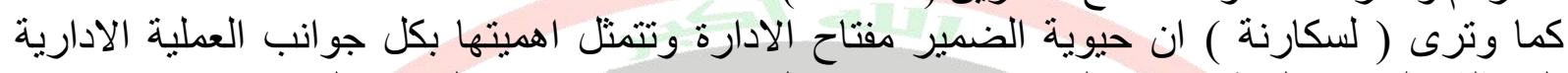

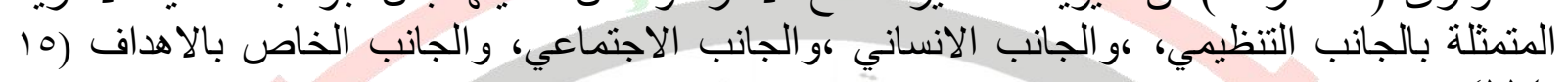

(1) $\leqslant$ :

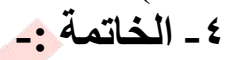

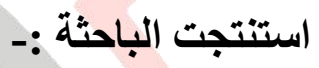

أن القيادات العليا من وجهة نظر التدريسين في بعض كليات و اقسام التربية البدنية و علوم الرياضة

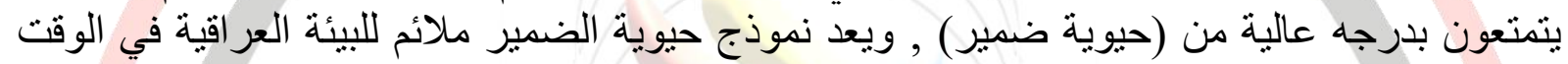

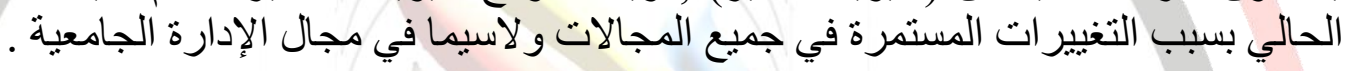

و وإن القيادات العليا من وجهة نظر التدريسين بمتلكون خر ائط عقلية تستند الى فلسفة المعرفة ، وهم ذوو

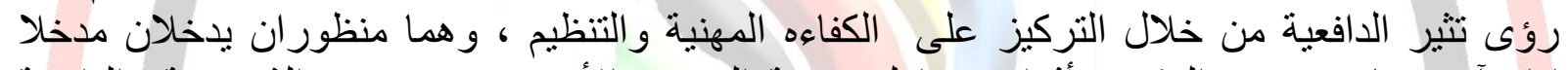
ادارياً صرفا ، وبنفس الوقت يتأثران بعوامل حيوية الضمير الأخرى وهي سحر الثخية وهية ولثطية والدافعية

واوصـــث الباحثة الى :-

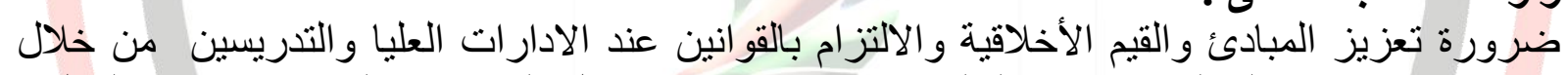

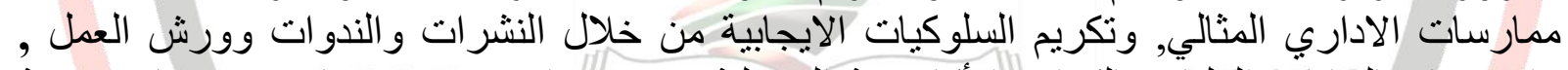

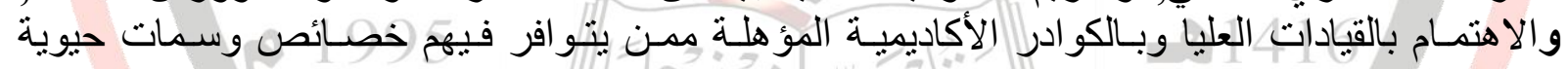
الضمير للاستفادة منها

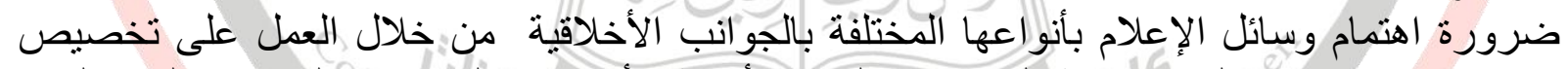

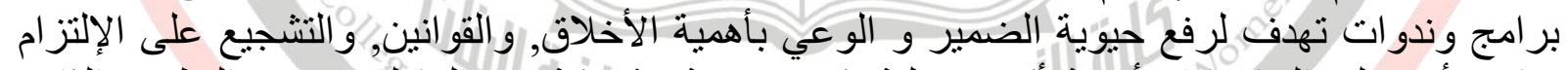

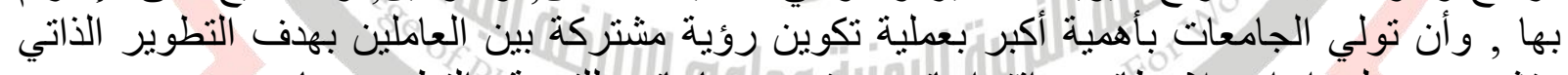

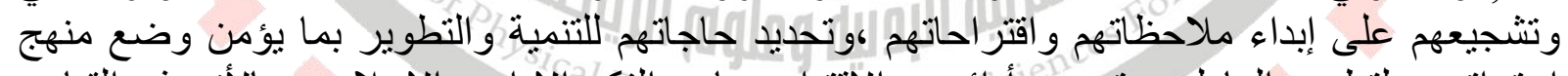

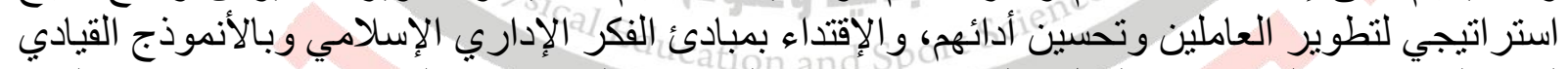

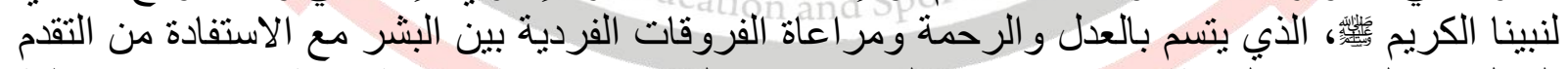

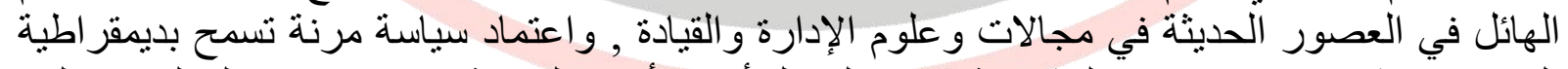

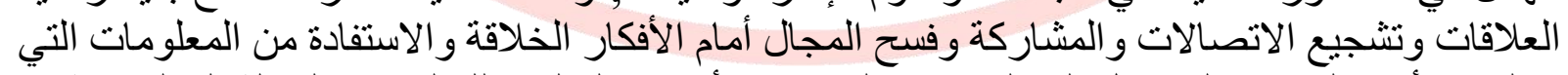

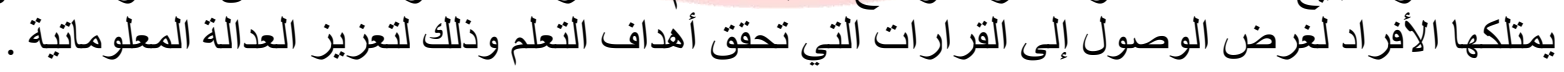
إجر اء در اسة ميدانيه في مجالات أخرى غير التي استخدمت في البحث الحالي , واجر اء دراسة مشابها

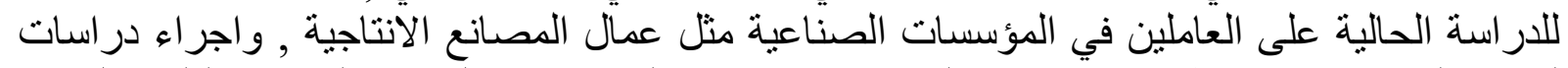
لقياس العلاقات الارتباطية بين حيوية الضمير وعدد من المتغيرات كالصحة النفسية ،القلق ،الجية الجمود 


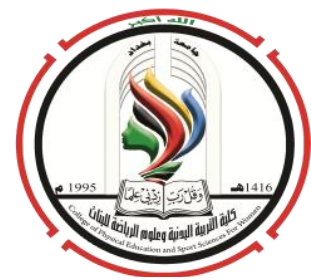

مجلة الرياضة المعاصرة

العاطفي ،التعاطف ،الانانية , دراسة مقارنمة في حيوية الضمير تبعاً لمتغيري المستوى الاقتصادي

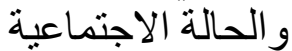

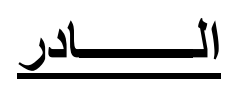

1 - احمد سليمان عودة وخليل يوسف ؛ الاحصاء للباحث في التربية والعلوم الانسابية : (دار الفكر

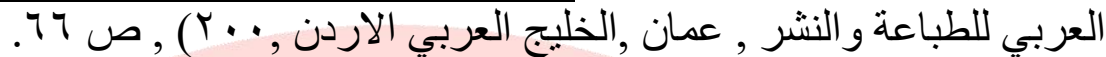

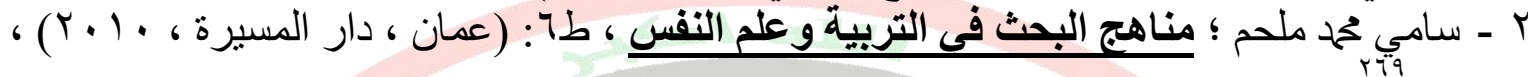
r - سالم القحطاني ؛ القيادة الادارية -التحول نحو النموذج القيادي العالمي :ا(لرياض , بدون الناثر r ع - سبع محم أبو لبده ؛ مبادئ القياس النفسى والتقييم التربوي : (عمان ، دار الفكر ناشرون وموز عون

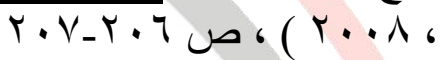
ه ـ صلاح الثنواني ؛ إدارة الافراد والعلاقات الإنسانية : (القاهرة , مؤسسة شباب الجامعة للطباعة

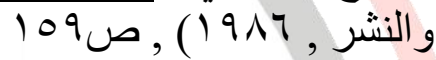
7 - صالح شافي العائدي ؛ الادارة اصولها وافكارها : (دمشق , دار العرب للار اسات و النشر و الترجمة

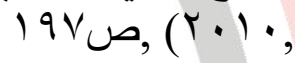

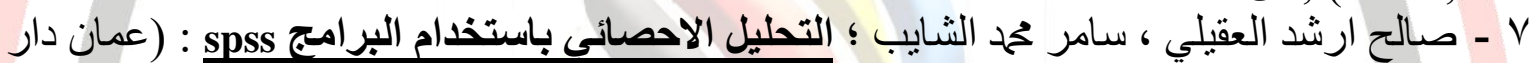

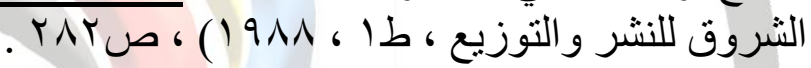

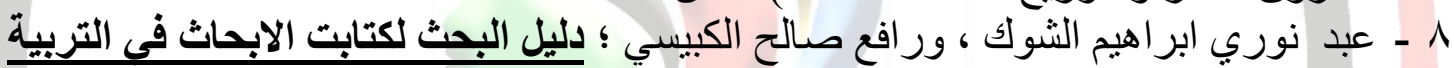

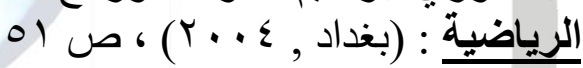
9 - عبد الهادي الجواهري (بذاد ؛ قاموس علم الاجتماع : (مصر ، الهيئة الهصرية العامة

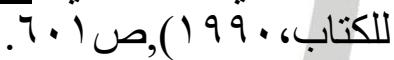

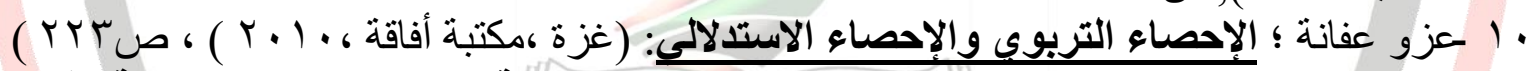

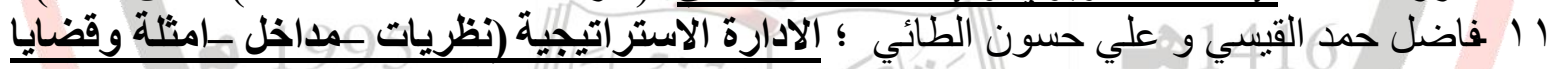

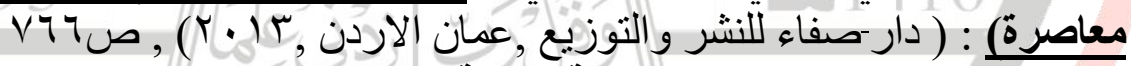

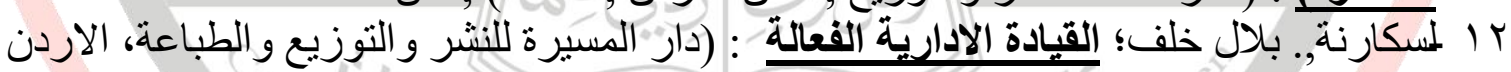

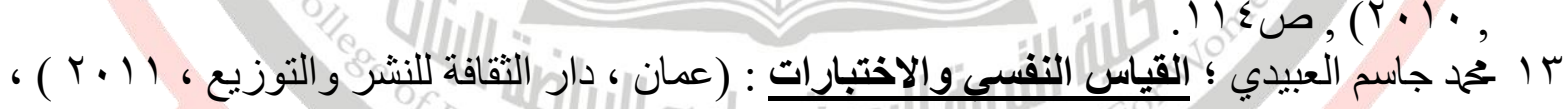
ro. ص 